\title{
Voltammetric Analysis of
}

\section{Graphene Oxide Modified Glassy Carbon Electrodes}

\section{Gina Mancini-Samuelson,}

Department of Chemistry

and Biochemistry

St. Catherine University

St. Paul, MN

Co-Authors: Alexandra Schmeltzer,

Denyce Alvarez, Alexandra Trusty

MARCH 25, 2020 ACS National Meeting

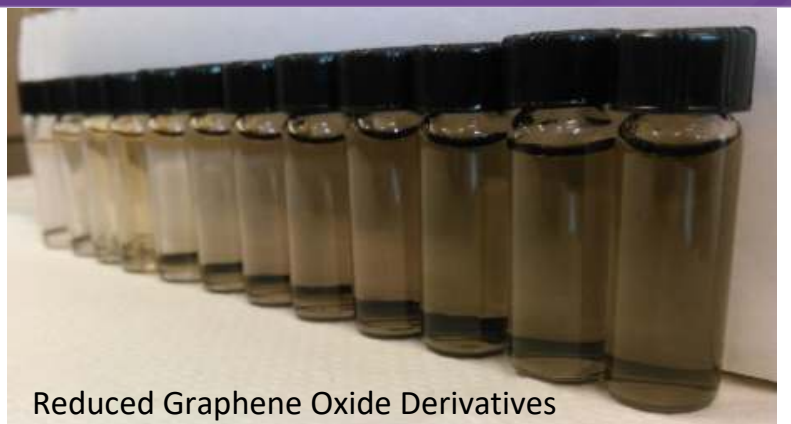

St. Catherine University 


\section{Graphene and Graphene Oxide Applications}

Potential New Products and Applications -

Flexible, transparent, small

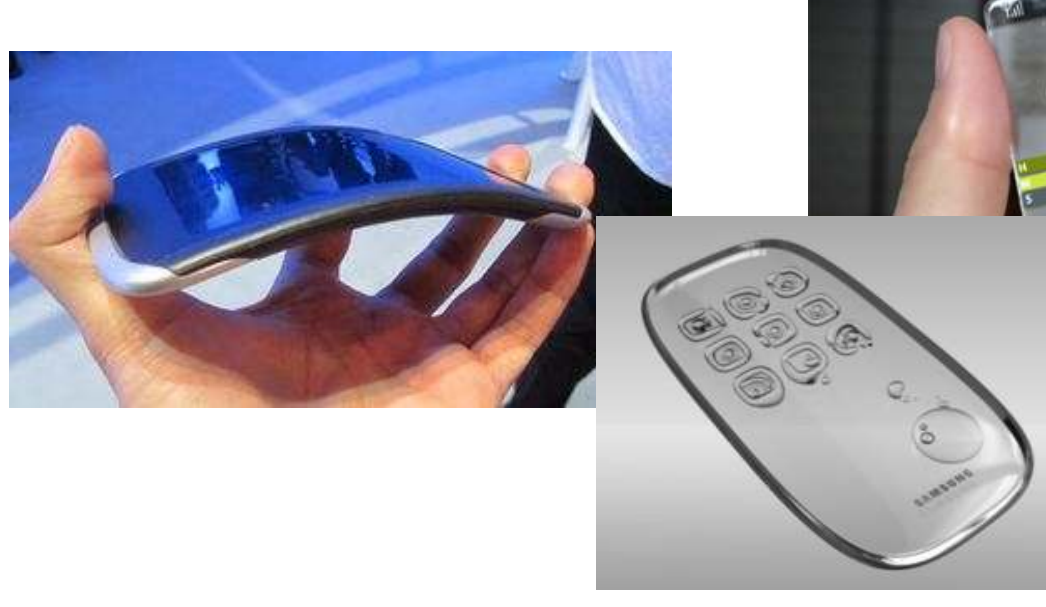

http://www.cellphonebeat.com/transparent-cellphone-concepts-fun http:/news.cnet.com.coming-to-a-printer-near-you-electronics-manufacturing

http:/artechnica.com/science/2016/a-graphene-patch-that-monitors-and-possibly-treats-diabetes. https://doi.org/10.1016/j.mattod.2019.01.007
St. Catherine University 


\section{Great interest in Graphene and Graphene Oxide}

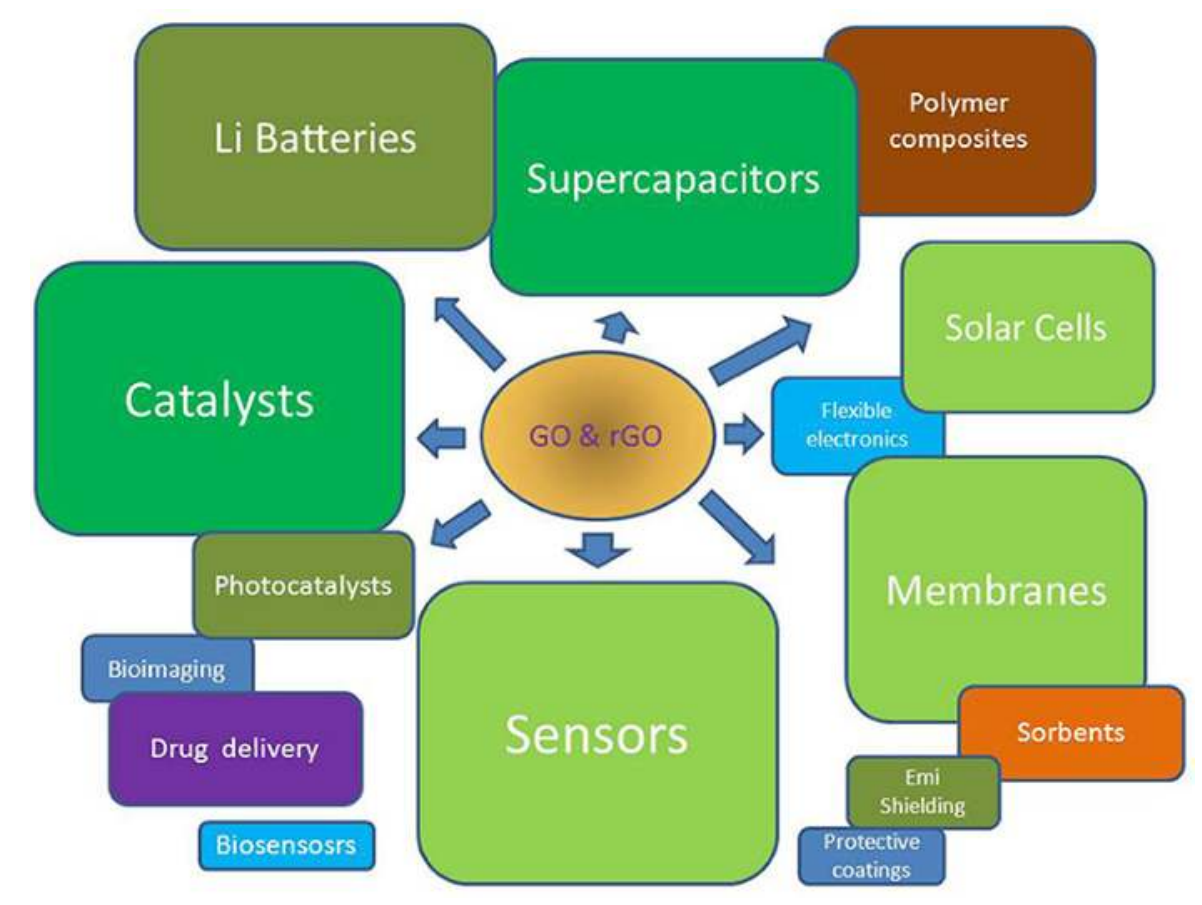

Contemporary and prospective Applications of GO and rGO. Size of blocks gives estimation of number of research publications areas.

According to the Web of Science. 


\section{Comparing Graphene to Graphene Oxide}

- Graphene

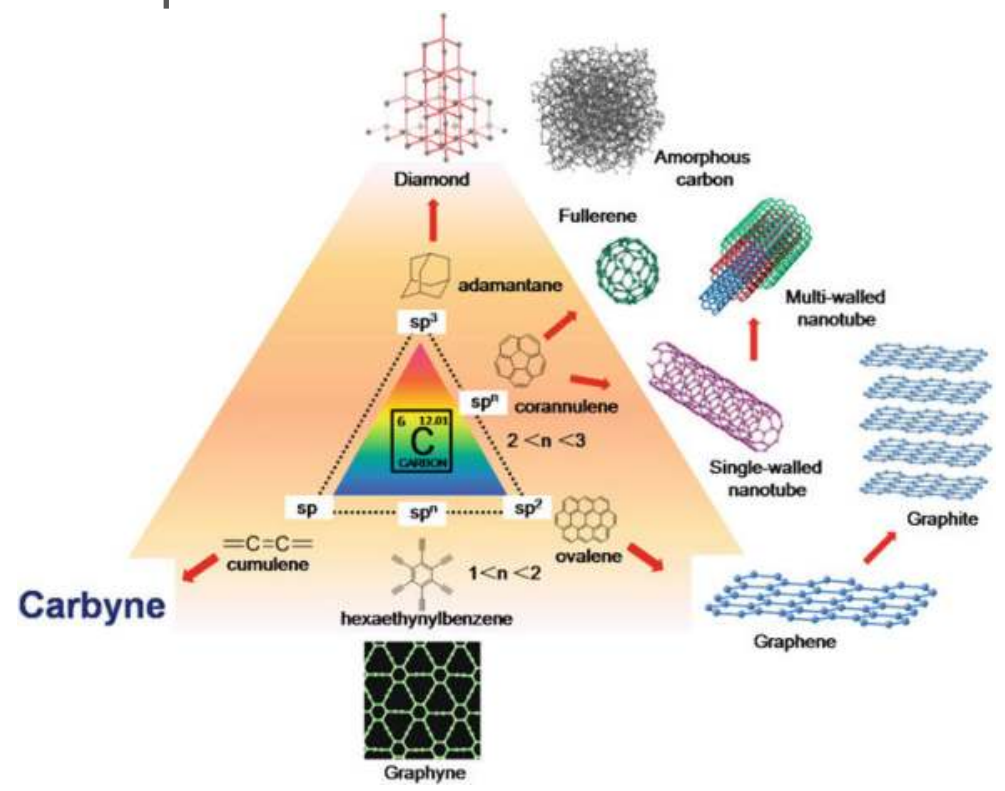

- Graphene Oxide

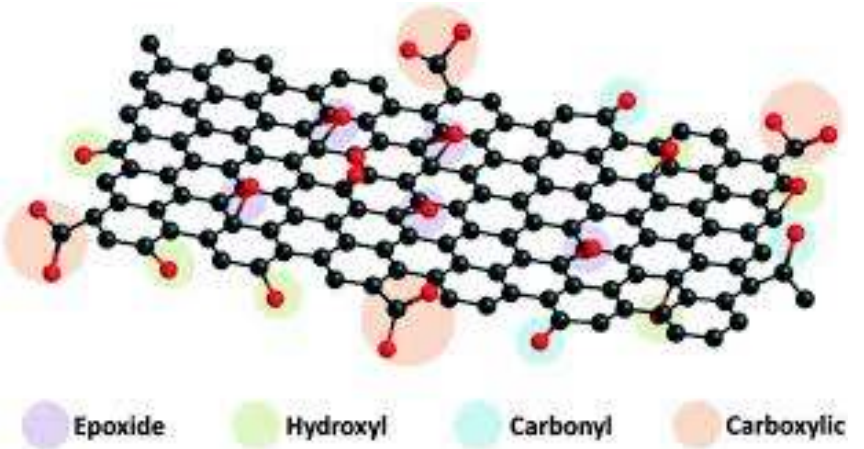




\section{Reduced Graphene Oxide (rGO) Derivatives}

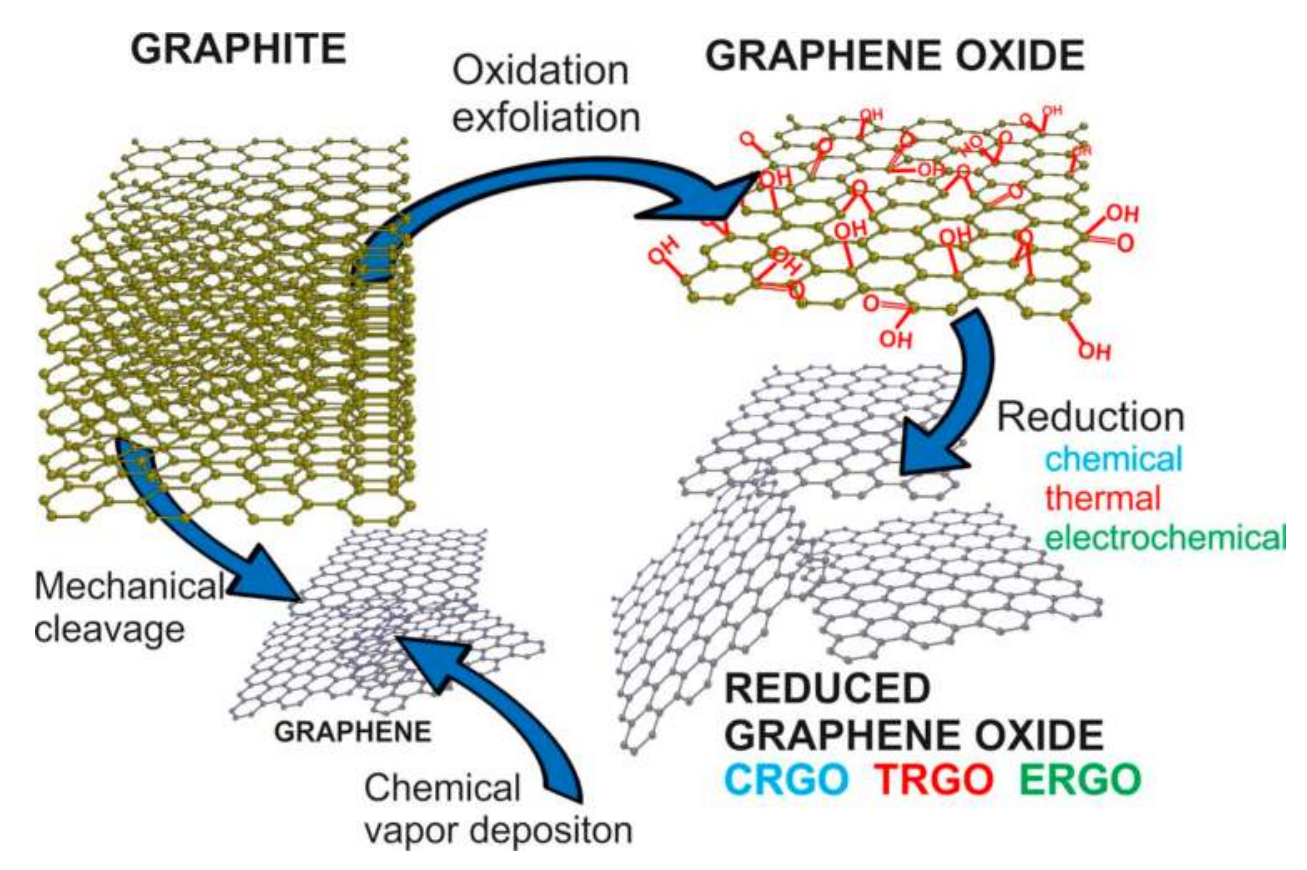

Reduced graphene oxide ( $\mathrm{rCO}$ ) is prepared by removing oxygen from the graphene oxide (GO) lattice.

Increase the $\mathrm{C} / \mathrm{O}$

rGO derivatives are intermediation forms of $\mathrm{rGO}$ reduction, $\mathrm{C} / \mathrm{O}$ varies 


\section{Focus of Study}

\section{Questions:}

1. Are there "greener" ways to reduce graphene oxide?

2. Can rGO derivatives (varying C/O GO) be stabilized?

3. How do the properties of rGO derivatives, particularly electrical performance, compare to graphene and graphene oxide? 


\section{UV-Vis spectroscopy, an easy way to track GO reduction}

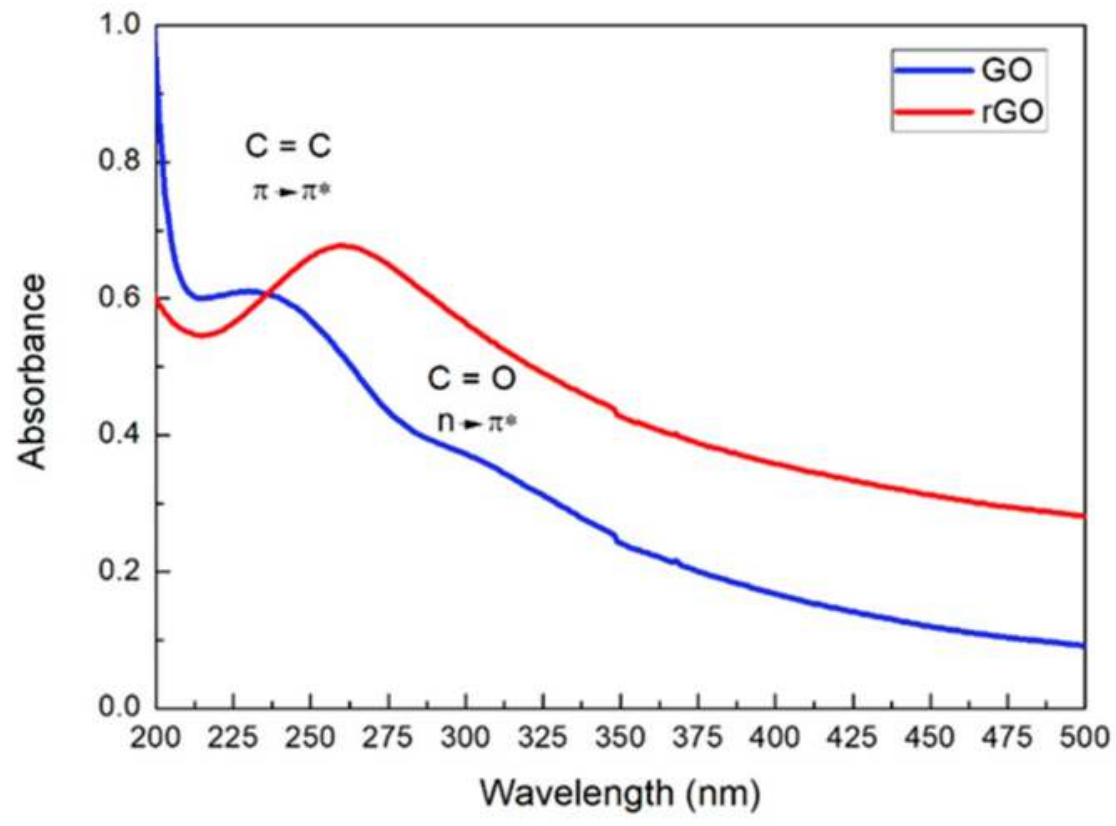

Graphene oxide red shifts from $230 \rightarrow 270 \mathrm{~nm}$ upon reduction 


\section{Ascorbic Acid as a Replacement for Hydrazine}

\section{"Vitamin $C$ is an ideal} substitute for hydrazine in the reduction of graphene oxide suspensions"

Fernandez-Merino et al.
TABLE 1: UV-vis Absorption Peak Position of $0.1 \mathrm{mg} \mathrm{mL}^{-1}$ Aqueous Graphene Oxide Suspensions after Completion of ductants (Sodium Borohydride, Pyrogallol, Vitamin C, and Hydrazine) and Bases (Ammonia and Potassium Hydroxide), with Indication of the Sample Acronyms Used Throughout the Text

\begin{tabular}{lcccc}
\hline reductant or base & sample acronym & $\begin{array}{c}\text { concentration of } \\
\text { reductant or base (mM) }\end{array}$ & $\begin{array}{c}\text { absorption peak } \\
\text { position (nm) }\end{array}$ & $\begin{array}{c}\text { time to reaction } \\
\text { completion (min) }\end{array}$ \\
\hline none (unreduced graphene oxide) & GO & & $231 \pm 2$ & \\
ammonia & N1 & 26 & $257 \pm 2$ & 240 \\
& N2 & 51 & $260 \pm 2$ & 240 \\
N3 & 103 & $256 \pm 2$ & 240 \\
potassium hydroxide & N4 & 206 & $257 \pm 2$ & 240 \\
& K1 & 0.8 & $252 \pm 2$ & 240 \\
K2 & 4 & $258 \pm 2$ & 120 \\
sodium borohydride & K3 & 20 & $258 \pm 2$ & 60 \\
& K4 & 100 & $251 \pm 2$ & 180 \\
& B1 & 0.5 & $251 \pm 2$ & 45 \\
B2 & 2 & $253 \pm 2$ & 45 \\
pyrogallol & B3 & 10 & $263 \pm 2$ & 15 \\
& B4 & 31 & $266 \pm 2$ & 15 \\
& B5 & 0.3 & $262 \pm 2$ & 120 \\
& P1 & 0.5 & $266 \pm 2$ & 60 \\
vitamin C & 1 & $266 \pm 2$ & 60 \\
& P2 & 2 & $268 \pm 2$ & 60 \\
& P3 & 0.3 & $268 \pm 2$ & 180 \\
P4 & 0.5 & $268 \pm 2$ & 15 \\
hydrazine monohydrate & V1 & 1 & $268 \pm 2$ & 15 \\
& V2 & 2 & $268 \pm 2$ & 15 \\
& V3 & 1 & $268 \pm 2$ & 15 \\
& V4 & 10 & & 15 \\
\hline
\end{tabular}

St. Catherine University 


\section{Big Picture $\rightarrow$ Can rGO derivatives be stabilized and studied in a "greener" way?}

Purpose of this study: Use the reducing agent, ascorbic acid to generate rGO derivatives and use simple methods to study stability and electrical performance.

\section{Methods}

1. UV-Vis max peak shift 230-270nm

2. Modified a glassy carbon electrodes and look at performance with a test sample 


\section{Graphene Oxide Source}

This GO is prepared by the Hummers Method.

Specifications:

- Composition Carbon (79\%) and Oxygen (20\%)

- Flake size 0.5-5 microns

- Thickness - 1 atomic layer

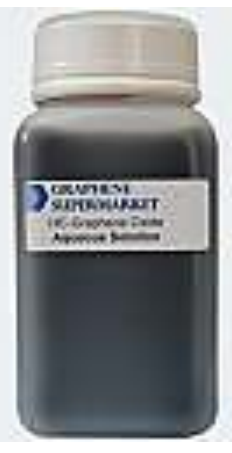

Highly Concentrated Graphene Oxide Dispersion in Water at least (60\%)

*from data sheet 


\section{First Method - UV-Vis Procedure and Controls}

\section{Procedure}

- Test tubes were prepared with increasing concentrations of ascorbic acid and a fixed volume of graphene oxide

- Samples were heated for 90 minutes in a $90^{\circ} \mathrm{C}$ water bath and then cooled to room temperature

- $\lambda_{\max }$ was monitored using a UV-VIS spectrometer

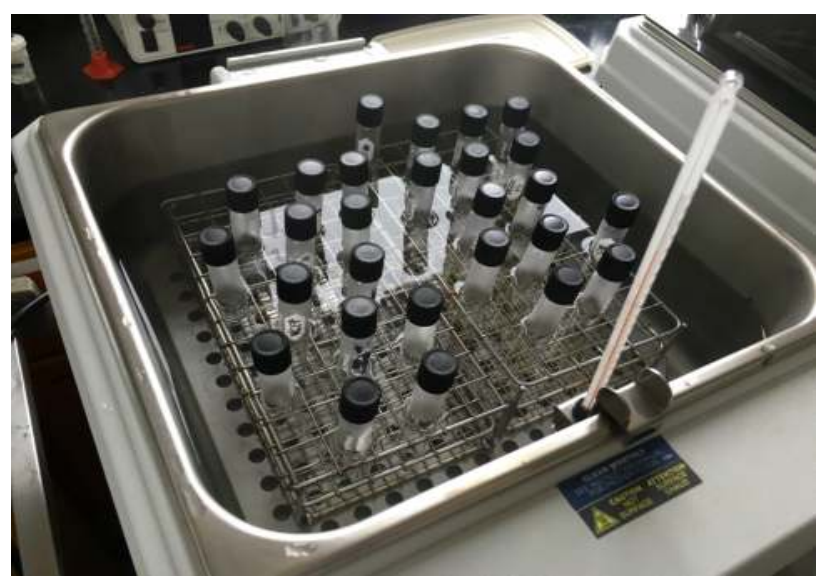
following careful ascorbic acid spectral subtraction 


\section{UV-Vis Controls}

1. GO + Ascorbic Acid $\rightarrow$ no peak shift $\rightarrow$ no reduction heat (or some catalyst) is required for the reduction

2. rGO derivatives $\rightarrow$ no peak shift for 48 hour

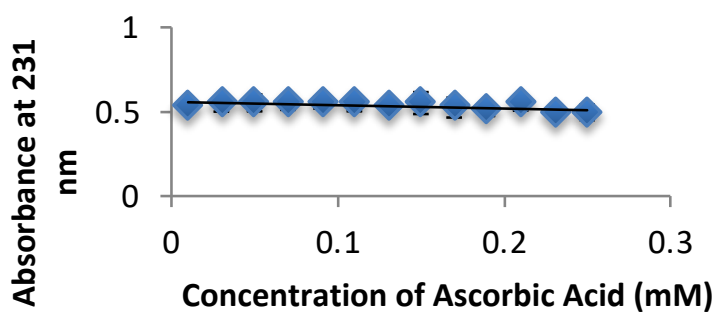

Figure 1: GO + Ascorbic Acid, no heat rGO derivatives are stable

\begin{tabular}{|c|c|}
\hline Minutes & $\lambda_{\max }$ \\
\hline 15 & 246 \\
\hline 30 & 246 \\
\hline 45 & 243 \\
\hline 60 & 246 \\
\hline 75 & 247 \\
\hline 90 & 245 \\
\hline 105 & 244 \\
\hline 120 & 247 \\
\hline 1440 (24 Hours) & 246 \\
\hline 2880 (48 Hours) & 247 \\
\hline
\end{tabular}

Table 2. The Effect of Time on Wavelength Maximum for $0.0625 \mathrm{mM}$ Ascorbic Acid and $20 \mu \mathrm{L}$ Graphene Oxide Sample

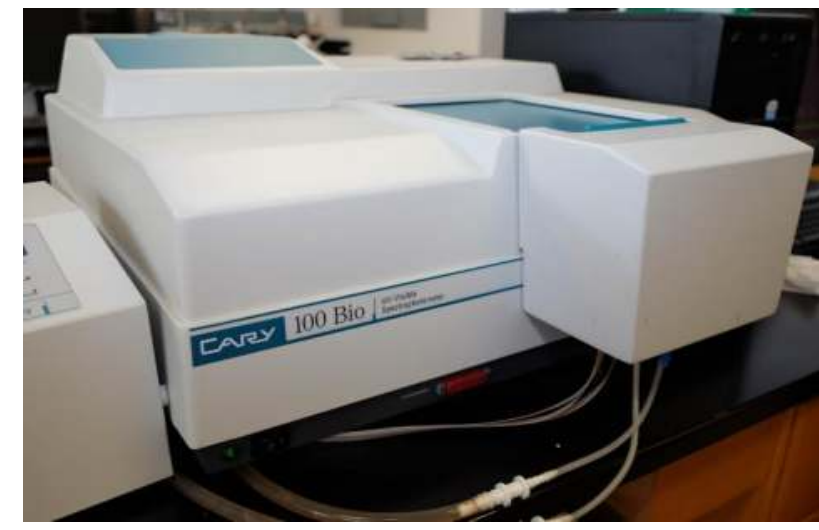

St. CATHERINE UNIVERSITY 


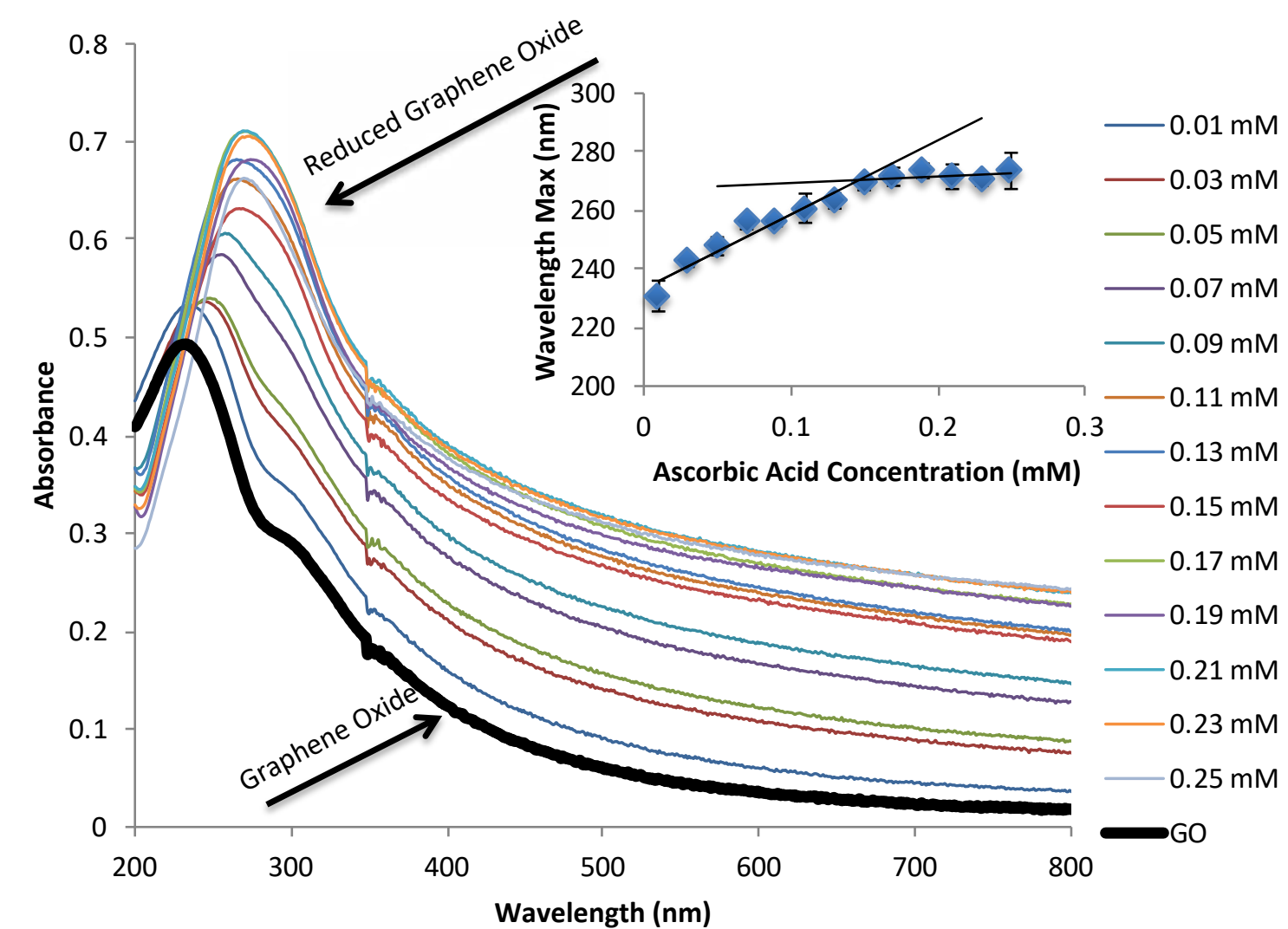

Figure 2: Titration of graphene oxide with ascorbic acid. The different colors represent varying $\mathrm{mM}$ concentration of ascorbic acid. Inset, extent of reduction, $\lambda \max$ versus $\mathrm{mM}$ ascorbic acid added to a constant volume of graphene oxide with heat.

\section{UV-Vis Findings}

- rGO derivatives were created

- UV-vis spectra were collected

- $\lambda$ max increases with increased concentration of ascorbic acid (mM)

Data collected on a Cary100BiouVVis spectrometer

\section{St. Catherine University}




\section{Depositing rGO Derivatives on Glassy Carbon Electrodes}

- A simple drop-casting method was used, Castro et al., but results were not reproducible.

- Deposition Method was adapted Chen et al.

$-1.5-0.6 \mathrm{~V}$ for 15 cycles at $25 \mathrm{mV} / \mathrm{sec}$ scan rate under $\mathrm{N}_{2}$ after $10 \mathrm{~min} \mathrm{~N}_{2}$ purge using Bioanalytical Systems, Incorporated (BASi) Epsilon Eclipse 3-electrode potentiostat/electrochemical workstation.

1. Castro, K. L. S. et al., Electrochemical response of glassy carbon electrodes modified using graphene sheets of different sizes. E. Int. J. Electrochem. Sci., 2018, 13, 71-87, doi: 10.20964/2018.01.02.

2. Chen, L. et al., Direct electrodeposition of reduced graphene oxide on glassy carbon electrode and its electrochemical application. Electrochemistry

Communications, 2011 , 13, 133-137, doi: 10.1016/j.elecom.2010.11.033. 


\section{Proposed Deposition Mechanism}

\section{Electrodeposition Mechanism:}

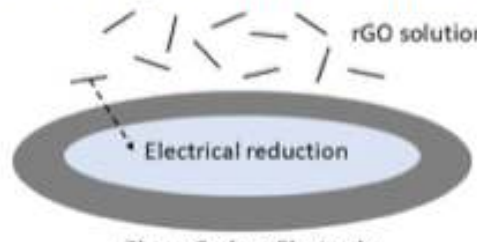

Glassy Carbon Electrode

Electrodeposition $-1.5 \mathrm{~V}$ to $0.6 \mathrm{~V}, 25 \mathrm{mV} / \mathrm{s}, 15$ cycles

Fiqure 3: Hiestredepostion of noO

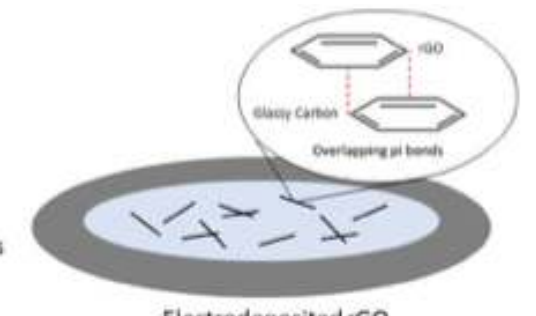

Electrodeposited $r$ GO

Figure 3: Deposition Mechanism for rGO 


\section{rGO Depostion and Testing of Electrochemical Properties}

- Deposit stable rGO derivatives on a glassy carbon electrode

- Use linear sweep voltammetry to monitor current produced in a potassium hexacyanoferrate (III) test solution in $1.0 \mathrm{M} \mathrm{KNO}_{3}$. Current, I, is related to conductivity, $\sigma$, via the following equations.

$\begin{array}{ll}\text { Equation 1 } & \mathrm{V}=\mathrm{IR} \\ \text { Equation 2 } & \mathrm{R}=\mathrm{L} \Omega / \sigma \mathrm{A}\end{array}$

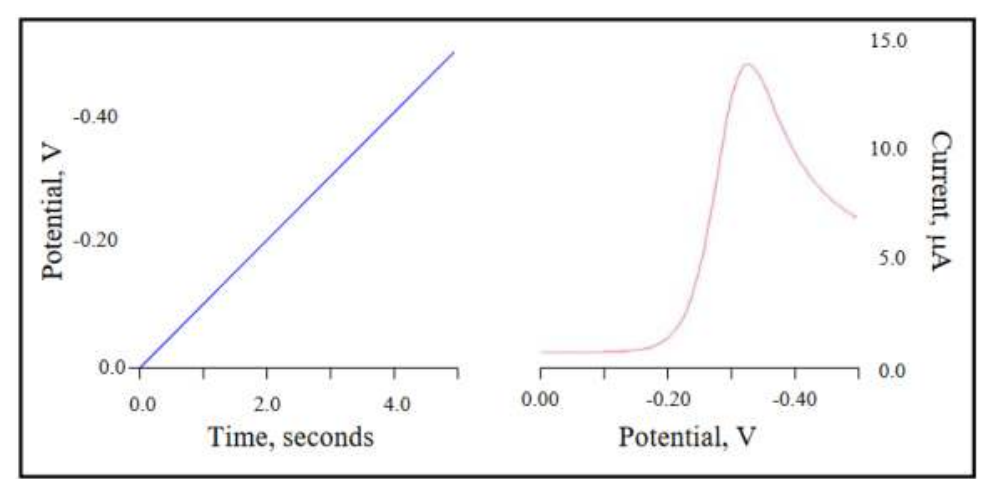

St. Catherine University 


\section{Experimental Parameters for a Trial}

- Trial included variable concentrations of ascorbic acid (0.01-0.20 mM) with fixed volume of GO (20 $\mu \mathrm{L})$ diluted to $10 \mathrm{ml}$ with type 1 water heated to $90^{\circ} \mathrm{C}$ for 90 minutes and then cooled to room temperature for 45 minutes.

- Same glassy carbon electrode used for trial

Glassy carbon electrode was polished with 1.0um diamond followed by alumina slurry $\rightarrow$ sonicate 45 minutes $\rightarrow 0.10 \mathrm{M}$ sulfuric acid cycling $(-1500 \mathrm{mV}-$ $800 \mathrm{mV}$ ) between experiments in a trial.

- Deposition Method under $1.5-0.6$ Ver $10 \mathrm{~min} \mathrm{~N}_{2}$ purge.

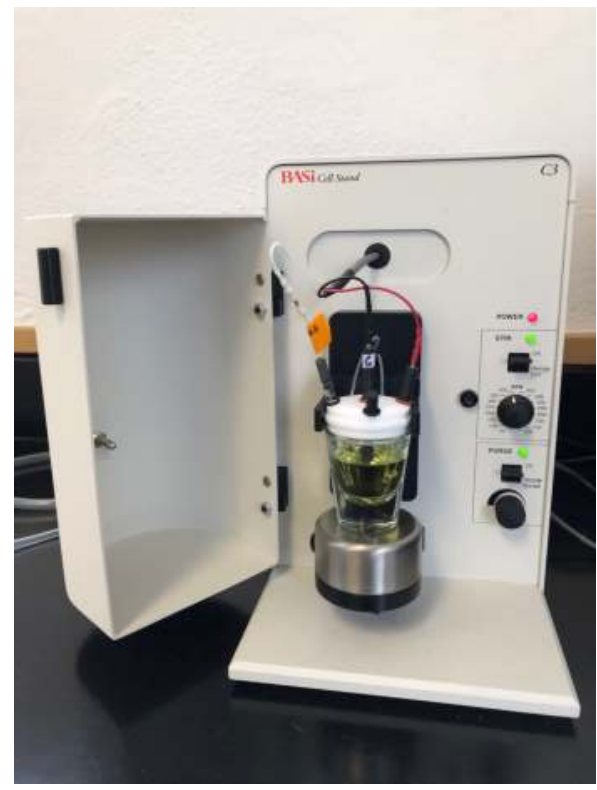

- Linear sweep experiment

$\mathrm{Ag} / \mathrm{AgCl}$ reference electrode and Pt wire auxilary electrode. Potassium hexacyanoferrate (III) test solution. 


\section{Trends from Linear Sweep Study of rGO Derivatives}

Extent of Reduction:

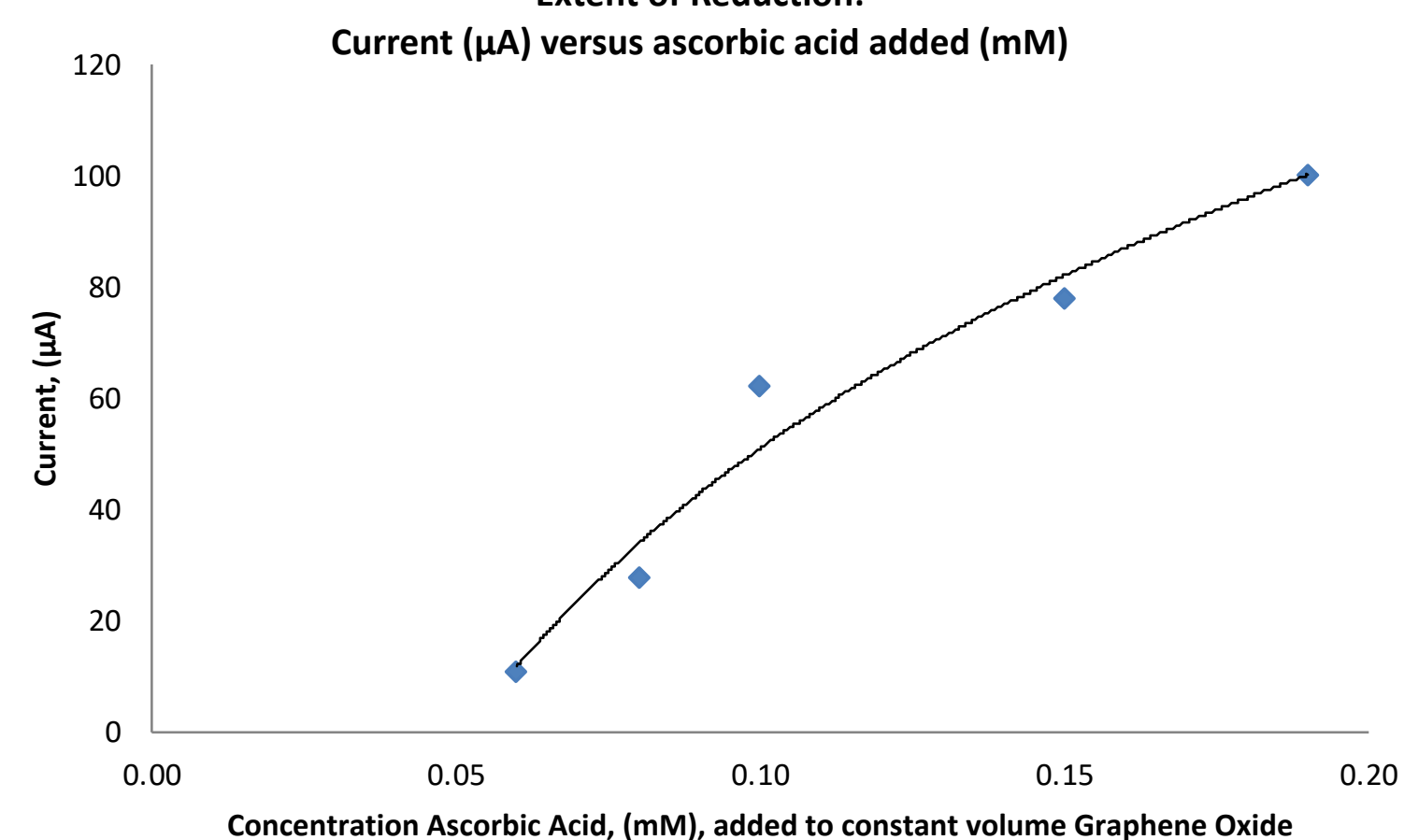

Figure 4: rGO modified glassy carbon electrode used in linear sweep voltammetry study of $8 \mathrm{mM}$ potassium hexacyanoferrate (III) test solution in $1.0 \mathrm{M} \mathrm{KNO}_{3}$. 


\section{Graphene Oxide Reduction Models}

From Lerf et al.

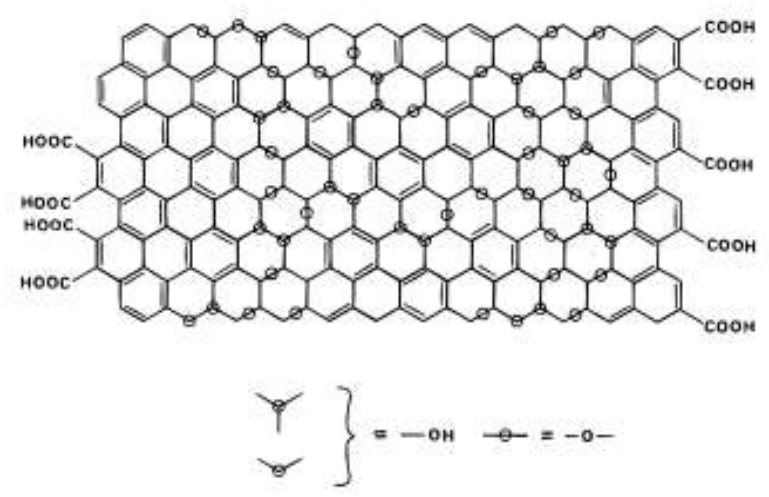

Figure 5: Lerf-Klinowski GO model.
From Dideikin et al.
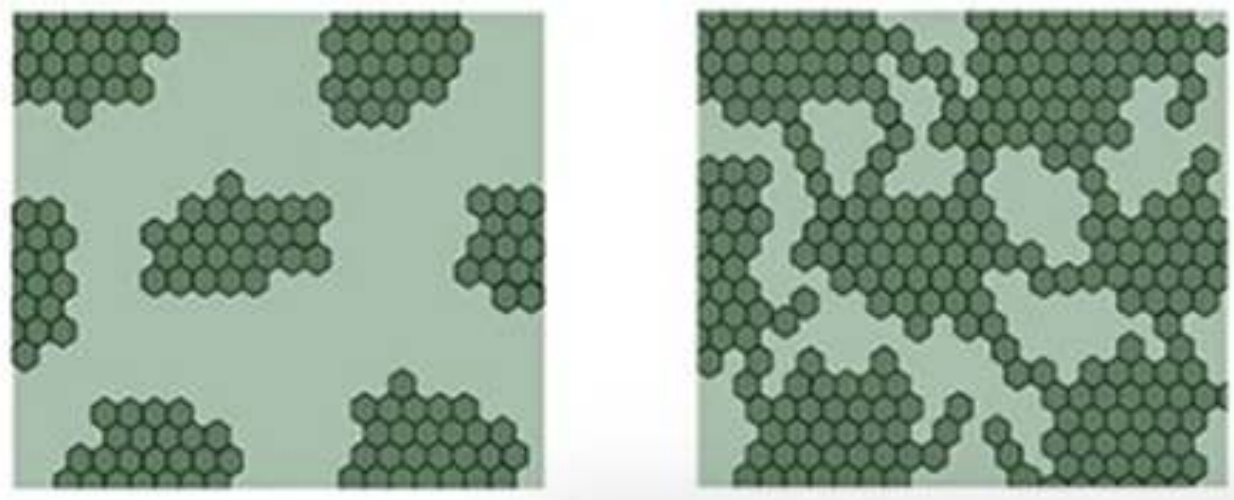

Figure 6: Schematic evolution of GO domain structure at reduction. Left - GO, Right - rGO. Dark green $\mathrm{sp}^{2}$ graphene regions, light green $\mathrm{sp}^{3}$ oxygen containing areas.

ST. CATHERINE UNIVERSITY 


\section{Next Steps}

- Further investigate the kinetics/thermodynamics of the GO reduction using simple methods.

- Investigate other ways to prepare stable rGO derivatives.

- Study the function and performance characteristics of rGO modified glassy carbon electrodes (stability, reproducibility, etc). 


\section{Conclusions}

1. Stable rGO derivatives can be prepared using the benign reducing agent, ascorbic acid.

2. The extent of reduction can be followed by UV-Vis spectroscopy by following the $\lambda$ max peak shift.

3. rGO derivatives where deposited on glassy carbon electrodes and current produced in linear sweep voltammetry can be measured using a test solution.

4. The current produced has two phases, possibly explained by the percolation threshold of the material. 


\section{Acknowledgements}

Financial Support for this project:

\section{- 3M Grant}

- St. Catherine University Summer Scholars Program

- St. Catherine University Assistantship Mentoring Program (A.M.P).

\section{Project Co-Authors}

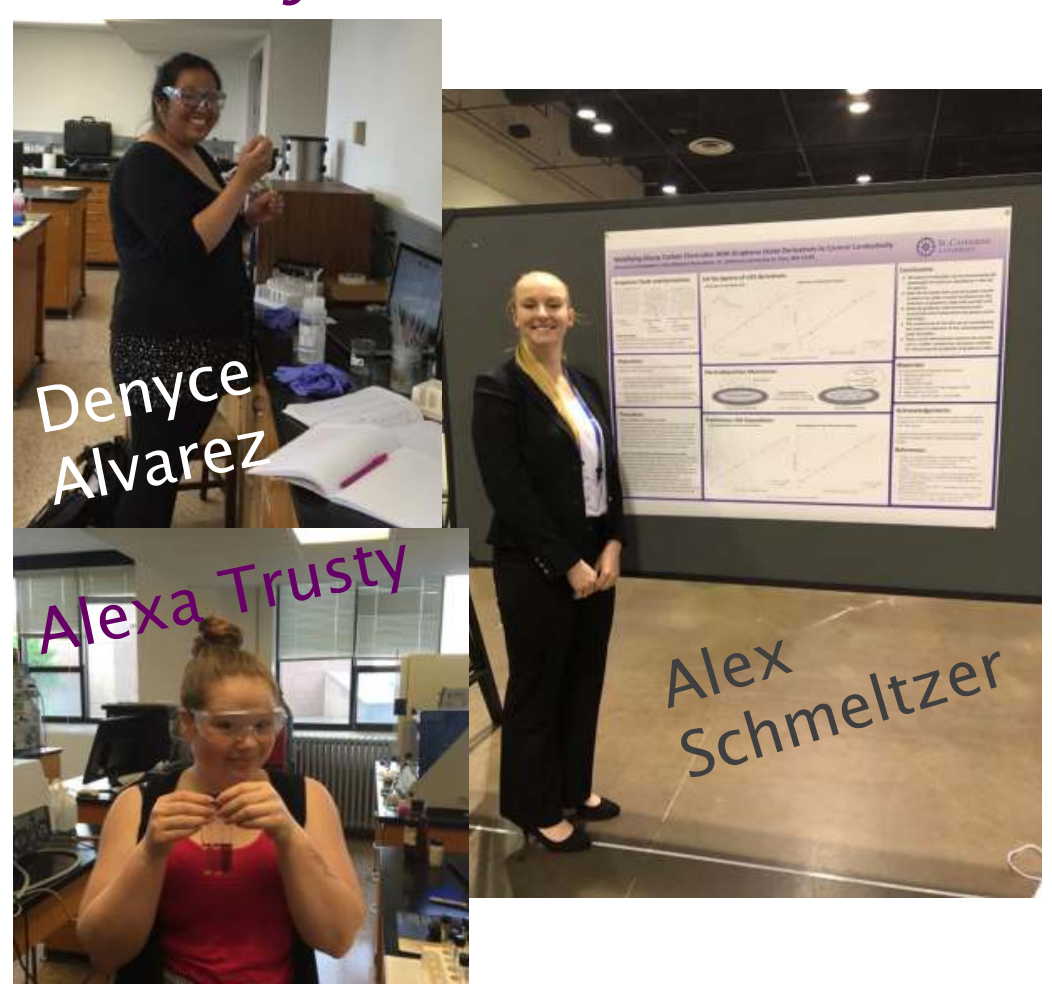

St. Catherine University 